\title{
A SURVEY ON DIFFICULTIES IN GIVING ENGLISH PRESENTATIONS EXPERIENCED BY STUDENTS AT HO CHI MINH CITY UNIVERSITY OF FOOD INDUSTRY
}

1 Ho Chi Minh City University of Food Industry; lekimcuong04101969@gmail.com

* Correspondence: lekimcuong04101969@gmail.com; Tel.: (+84) 986317773

Citation: Le, Cuong. (2021, August 18). A survey on difficulties in giving English presentations experienced by students at Ho Chi Minh City University of Food Industry (HUFI). https://doi.org/10. 31219/osf.io/xwn72

Academic Editor: Cuong Le

Received: August 18, 2021 Accepted: August 18, 2021 Published: August 18, 2021

Publisher's Note: MDPI stays neutral with regard to jurisdictional claims in published maps and institutional affiliations.

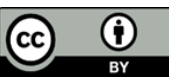

Copyright: (C) 2021 by the authors. Submitted for possible open access publication under the terms and conditions of the Creative Commons Attribution (CC BY) license (https://creativecommons.org/license s/by/4.0/).

\begin{abstract}
Nowadays, oral presentation plays an important role in the university environment. Nevertheless, most students still do not have enough experiences and skills in presenting, which leads them to deal with various problems. In an effort to investigate their presenting difficulties, this research aimed to point out: (1) the students' attitudes towards the importance of oral presenting skills, (2) the difficulties when presenting they would encounter, and (3) the factors causing the challenges and some suggested solutions. Specifically, the investigation has been carried out in the form of survey research, with a hundred and forty students at Ho Chi Minh City University of Food Industry participating as informants. The main data collection instrument was the online survey questionnaire done by those students. The research has indicated that the students' poor linguistic proficiency, including their pronunciation, nonverbal communication, lack of interaction, all found it hard for them to be comprehended. Furthermore, the data collection has confirmed that the assessments and comments from the institution's lack of high-quality equipment and facilities also related to these students' poor presenting performances. For those reasons, the investigation recommends that teachers and institutions should make greater efforts in educating oral presenting skills to better their students' presentation skills. On the students' part, it is essential to be more aware of the preparations and to have suitable strategies for enhancing presentation abilities to meet the expectations of future work.
\end{abstract}

Keywords: difficulties, English, presentations, oral presenting, students, university

\section{Introduction}

\subsection{Rationale of the research}

English has recently been taught throughout Vietnam. English has become a compulsory subject, especially in schools, colleges, and universities. Now, we are living in an international society where English has steadily become a global language that is used by the majority of people around the world to study and work. As a global language, English is commonly utilized in almost every field on the planet. Vietnam has long recognized the value of English in advancing economic growth and strengthening international relationships. There is no doubt that English is the bridge to connect Vietnamese culture and its people to the rest of the world. In the first place, Vietnamese individuals began learning English as their job requirement, but today they learn for a variety of reasons. Some learn for their future career; some learn for their desire to widen their knowledge base, and still, others might learn for interest. English is a compulsory subject for university students as well as job requirements after graduating. It goes without saying that the efficacy of English teaching and learning in schools should be considered. 
Nonetheless, many English learners, particularly students in universities and colleges, struggle with how to learn English effectively. In spite of the fact that most of the students have been learning English since they were at secondary school, they are not proficient in learning it. As a result, greater emphasis should be placed on developing students' ability to learn English. This problem might be caused by a variety of factors, but the most common one is students' lack of motivation and interest to learn it. Even when they have enough knowledge to passionately take part in the lessons, many of them remain disengaged and reject interaction with their teachers. Consequently, regardless of having learned English for many years, many students still struggle to communicate with foreigners. Thus, it is essential to identify the most effective teaching presentation methods for students. Effective English learning in class depends on how the teacher can maintain their students' interests that motivate them to attend the course. Motivation, according to many studies, has a significant impact on the efficacy of the teaching and learning process. Highly motivated learners are more likely to be more successful than those who are not.

Additionally, in English classes, presenting activities are now becoming more prevalent. Those activities are great ways for students to practice all language systems such as vocabularies, grammar, etc., and skills like listening, speaking, reading, and writing. Students who are good speakers are better communicators because they can easily explain their thoughts. Presentations can help students better their public speaking skills and enhance their enthusiasm for English. Moreover, they can also help them gain confidence, which is a trait that most individuals need for their work.

Hence, in order to develop students' English presentation proficiency, this research is being undertaken to evaluate the difficulties in giving oral English presentations experienced by students and how to tackle this issue. This study is expected to help the students in some manners to find suitable strategies to overcome these challenges.

\subsection{Aims of the research}

The objective of this research is to investigate the difficulties in giving English presentations experienced by students at Ho Chi Minh City University of Food Industry. The research's three primary objectives are mentioned below:

- Analyzing the attitudes of students towards the importance of oral English presentations

- Identifying the factors influencing the students' presentation abilities

- Presenting some suggested solutions for students on how to boost their presenting skills

So as to accomplish the above-stated purposes, the research aims to answer the following research questions:

1. What are the students' attitudes towards the importance of oral English presentations?

2. What factors influence the students' presentation abilities?

3. What should students do to boost their presenting skills? 
The researcher conducted the following methodologies to complete the research:

- $\quad$ Utilizing both quantitative and qualitative analyzes

- $\quad$ Implementing survey questionnaires for students

\subsection{Design of the research}

The research is divided into four sections:

Section 1: Introduction: including the rationale, aims, methods of the study, and a thesis overview in this article.

Section 2: Literature review: discussions the thoughts and issues on oral English presentations

Section 3: Including three parts, the research:

- Methodology and data collection: this part consists of the research techniques, the research participants, data collection instruments, and processes.

- Results, findings, and discussions: this part mentions the data collection analysis and the findings of oral presenting utilization in English learning.

- Suggestions for effectively utilizing oral English presentations effectively: this part relates to some suggested solutions for students to enhance their presenting skills.

Section 4: Conclusion: discusses the research's limitations and recommendations for further investigations.

\section{Literature review}

Many studies have been done on the challenges that students encounter during presenting. Nguyen (2010) reported that students at Phuong Dong University consider poor English proficiency to be the most common difficulty. Since their English is not good enough to express themselves correctly, their confidence is affected. This prevented them from delivering a successful presentation. A study at Al Aqsa University showed that over $75 \%$ of students found it challenging to apply body language and gestures during their speeches (El Enein, 2011). Furthermore, students often focus on getting the grammar right rather than paying attention to their overall fluency (p. 105). This finding is relevant to data obtained from the studies at Sarawak University and Al Quds Open University, as many students identified pronunciation as a common difficulty (Kho, Abdullah, \& Leong, 2015; Al Nakhalah, 2016). The behavior of their peers and instructors while presenting could have an impact on their performance too. Al-Nouh et al. (2015) revealed that students feel uncomfortable when teachers interrupt the presentations to give comments when classmates start talking and laughing at each other or when they enter the class late. Anxiety is another common issue that students face when presenting. When students become nervous, they can display signs such as making unnecessary mistakes, stammering, panicking and perspiring, losing control over what would be said as well as fidgeting, procrastinating, stuttering, and avoiding behavior (Djahimo, Bora, \& Huan, 2018, p. 190). Another major problem that some students have to deal with during presenting is time limitation (Hanifa \& Yusra, 2018). Researchers believe that delivering a presentation in a defined amount of time can be quite frustrating since students have to cover a significant amount of information on the topic (p. 321). 
Studies have also noted a variety of factors as to why students perceive English presentations as demanding. Through data collected from the questionnaire, IELTS type oral assessment and interview with international students, Woodrow (2006) found that students from CHCs (Confucian Heritage Cultures) like Japan, China and Korea tend to be more anxious than students from other nationalities when it comes to speaking English in an oral presentation, due to the fact that they suffer from a passive learning style in their home countries. Linguistic problems were another common cause of students' oral presenting issues. These issues refer to students' lack of English proficiency when giving oral presentations. One possible explanation for this is because students did not have many opportunities to communicate in the target language since they preferred to communicate in their mother tongues, particularly outside the classrooms (Kho \& Leong, 2015). Other small factors could influence students' perceptions of English presentation difficulties, such as their academic year. Generally, students have positive attitudes towards in-class presentations because of all the experience and exposure to English oral presentations during their first year (Matsuoka, Matsumoto, Poole, \& Matsuoka, 2014).

Previous researchers have also considered the expectation of students in English oral presentations. Otoshi and Heffernen (2008) pointed out that students believe that in order for a presentation in English to succeed, it must have three components: clarity of speech and voice quality; correctness of language; and interaction with the audiences. Additionally, these students also did not seem to mind overall grammatical mistakes in presentations. Miles (2009) observed that when students do oral presentations, they are not interested in learning traditional presentation skills or acquiring a tangible skill for their job, but use oral presentations as a way to learn how to communicate their ideas in an informal way. Soureshjani and Ghanbari (2012) noticed that students regarded details of the presentation to be a crucial element in a successful English presentation.

Despite the numerous studies and research on difficulties in English presentations, certain facets of this phenomenon are still being overlooked. Therefore, the goals of this study are to investigate clearer this reality that many students still struggle with. The study's results could also help students gain more solutions to advance in their English presentations.

\section{Materials and Methods}

One hundred and forty students at Ho Chi Minh City University of Food Industry were investigated. Despite presenting in English regularly, students still have run up against lots of difficulties. Besides mainly focusing on difficulties, the survey also suggested some ways that students have to settle their issues.

The test instrument employed in this survey was an online questionnaire made from Google Drive. This tool lets participants respond quickly and allows results to be received immediately in the form of the calculated proportions. The questionnaire consists of 13 questions divided into three parts: Part I (General information) contains 5 questions about background related to studying English of participants; Part II (Difficulties) contains 5 questions on the level of dealing with problems while giving English presentations; Part III (Some suggested solutions) includes 3 questions offering some students' preferred resolutions to overcome their issues as well as to improve their English presentation skills.

Before administering the questionnaire, a small group of about 5 students would be invited to examine whether the questionnaire's content was clear or not, it was called a pilot period. From their feedback, the questionnaire was modified to be more logical. Then, a link would be shared with students on social media. Participants would click on the link, and answered all questions required. It only took each student about 5 minutes 
to complete the questionnaire. After one month, from April 20 to May 20, the research's target was completed with 140 responses.

In the questionnaire's first part, participants only chose one suitable answer for each question. In the next section, students would rank the level of difficulties they faced on a multiple-choice grid, ranging from "Always" to "Never". Lastly, at the end of the questionnaire, students finished three multiple-choices questions.

174

\subsection{Participants}

This research was undertaken at Ho Chi Minh City University of Food Industry in Vietnam. The research participants represent both Natural Science and Social Science disciplines such as Accounting, Business Administration, Food Technology, Information Technology, etc. Oral presentations, as a matter of fact, play a crucial role for students to get the opportunities to enhance their English language proficiency. The data collection was mainly analyzed the students' presenting performances of more than 140 students from different disciplines.

\subsection{Procedures}

The data collection and analysis are presented by the following steps:

- First, online survey questionnaires were given to the students through social media.

- $\quad$ Then, the data were integrated and categorized once they were collected.

- $\quad$ After that, the data were shown and analyzed in the form of tables, diagrams, and figures.

In the next part, data findings and analysis will be described and discussed.

190

\section{Results and Discussion}

Below is the detailed analysis of the research's findings and discussion, which is classified into two parts: students' attitudes towards and difficulties influencing their presenting performances. The findings' data is presented in the form of pie diagrams, providing the percentage level to be clearly observed.

\subsection{Gender different challenges in facing presenting difficulties}

The following pie diagrams (from Figure 1 to Figure 5) were the data of some general information of the participants.

The pie chart in Figure 1 showed some general information about students studying English. It was clear that the percentage of female participants taking this questionnaire was $65.8 \%$ higher than the male ones. There was $60 \%$ of students had been learning English from 5 to 10 years while students who had been learning English more than 13 years were $50 \%$ lower (Figure 2).

.

.

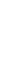

79

30

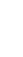




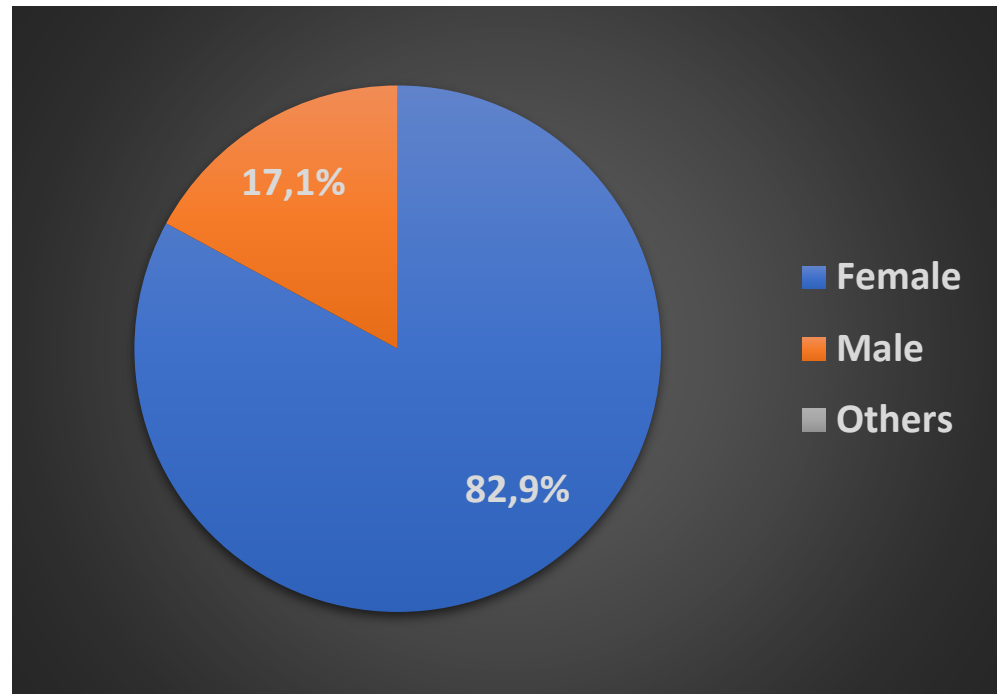

Figure 1. Survey population

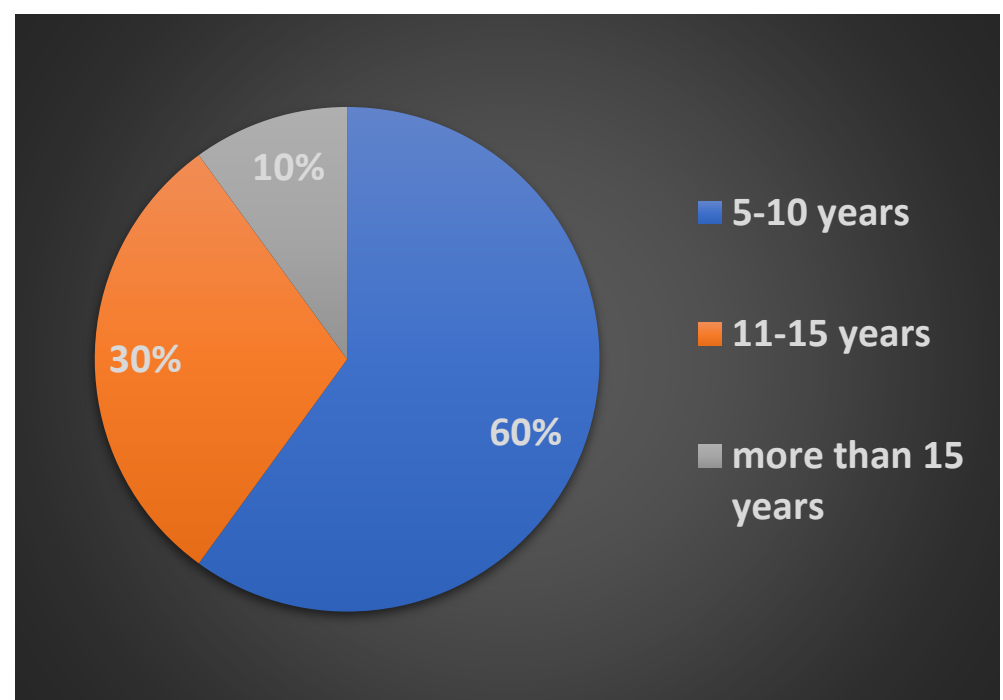

Figure 2. Time distribution of English learning

When asking about the frequency of giving oral presentations, 30\% of students chose "Once a week" and the figures for students choosing twice a week was $15.7 \%$, which was twice of that choosing every lesson (Figure 3). The rate of students who considered presentation skills in English very important was over triple that of neutral counterparts (Figure 4). 




Figure 3. Students' frequency of giving English presentations

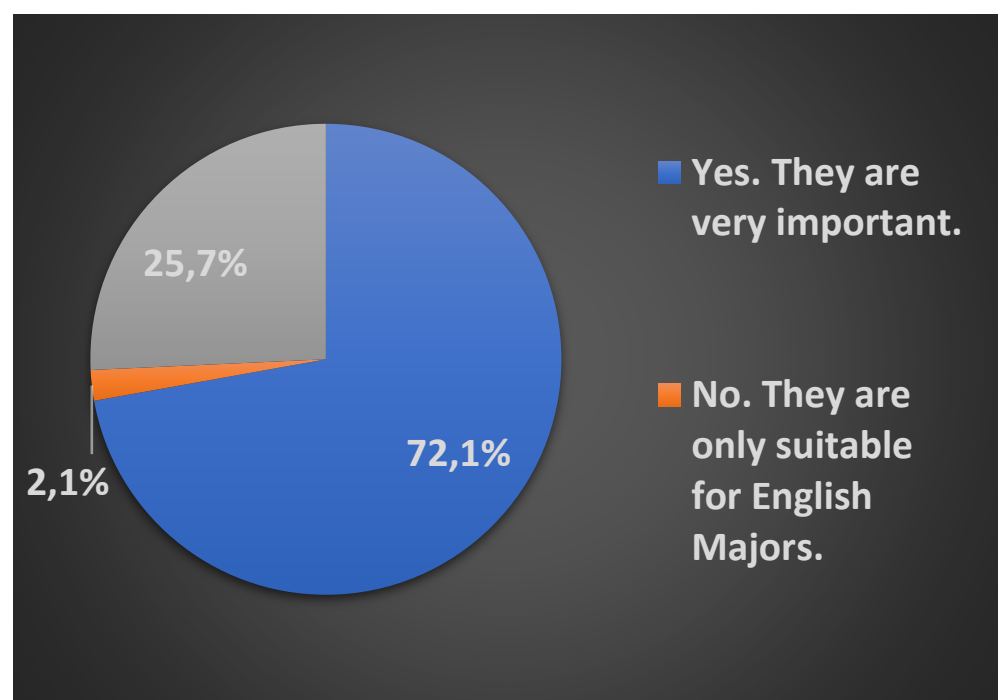

Figure 4. Students' opinions on the importance of presentations

Besides, the proportion of students always facing difficulties in giving an English presentation accounted for $20 \%$ while the rates of students often and sometimes having problems in English presenting were 54\% and 22\% respectively (Figure 5). 




Figure 5. Students' frequency of having difficulties in English presenting

\subsection{Difficulties influencing English presentation performances}

The next five figures (from Figure 6 to Figure 10) were the bar diagrams of various problems which students frequently dealt with.

Figure 6 pointed out three problems related to the contents of the presentations. Generally, the participants chose the state "Often" and "Sometimes" higher than other states. In detail, "Unfamiliar topics" could be considered as the most common difficulty. Of the 140 participants, only 10 people reported that they rarely had this difficulty, while the rates in the states remaining were quite high. For instance, there are 10 students always confronted this one; and those who often or sometimes did were in a range from 50 people to more than 60 people. The noticeable reason was that they did not have enough presentation skills. It was just simply because the education in Vietnam did not focus much on soft skills for students in general education. Until attending universities, they were required to give presentations without any presenting guides. Besides, the first-year learning also was not equipped them with enough experiences about presenting skills; that was why this difficulty was still happening very often.

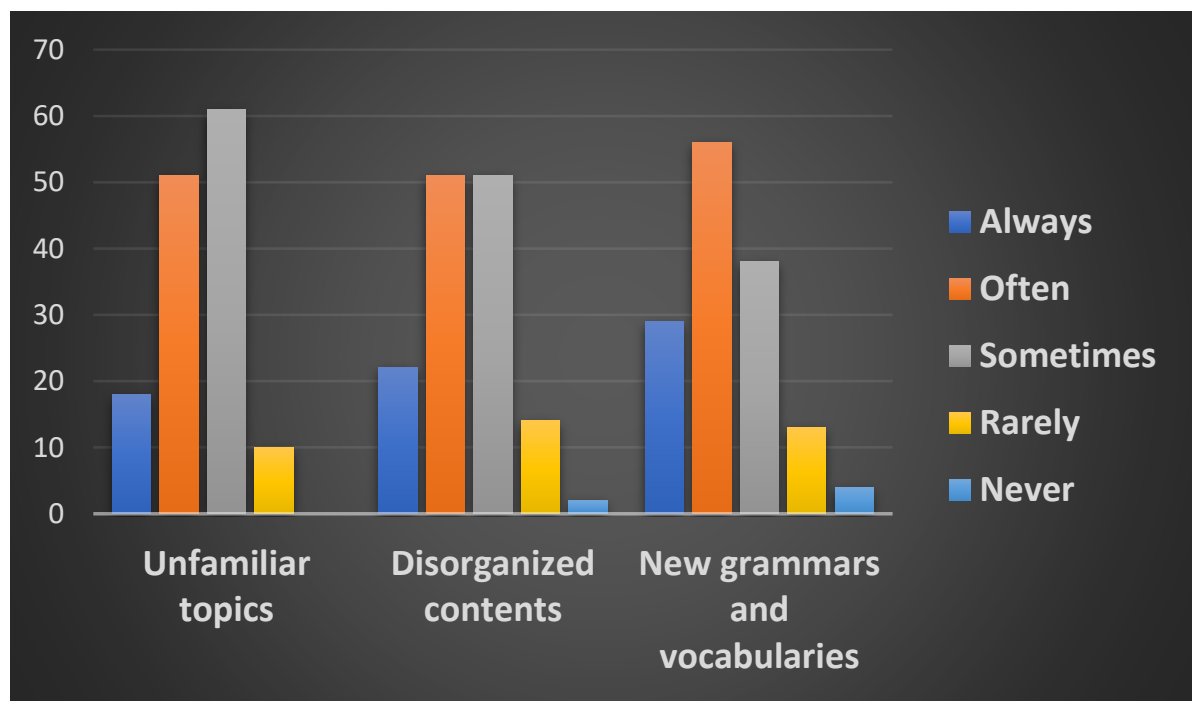

Figure 6. Problems related to the presentation contents 
The followings were three problems related to the physical settings (Figure 7). As a whole, the chart presented the rates in the state "Sometimes" which was much taller compared to the rest. Nevertheless, it could be seen that "Poor quality equipment and facilities" was the most popular one for students. When compared to the remaining difficulties, both 3 states "Always", "Often" and "Sometimes" all had higher rates with the number of choices were 11. 24, and 57 people in turns. Besides, 39 students who voted for "Rarely" also was the highest rate among these difficulties, which was also good evidence to have a remarkable mark in proving that it seldom happened to students. The reasons for this could be objective or subjective. Objectively, Ho Chi Minh City University of Food Industry had recently renovated. The equipment was getting better and better day by day; however, sometimes some unexpected issues with the equipment were inevitable. Subjectively, not all the students could achieve the modern, expensive laptops. Some of them even did not have laptops for their own. Thus, they probably had to deal with technical problems such as the laptop did not fit in with the school's equipment.

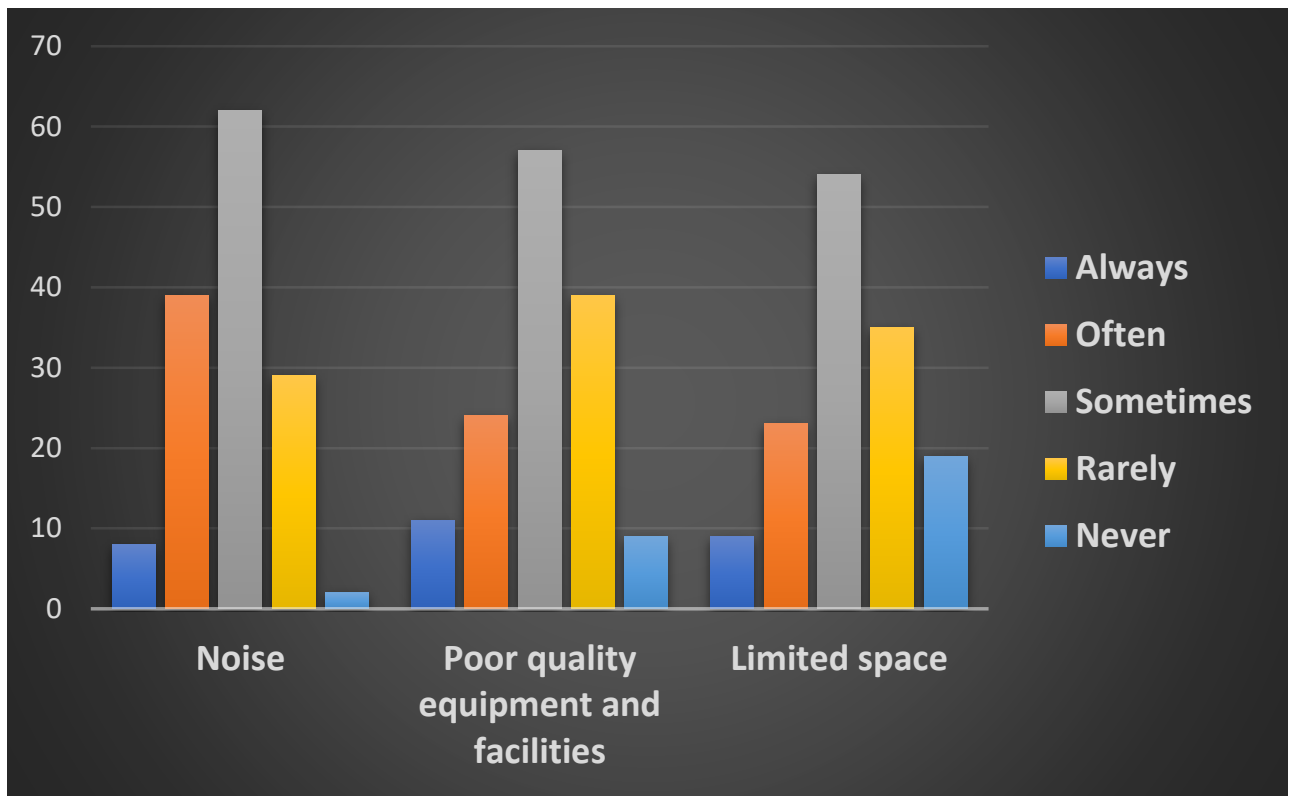

Figure 7. Problems related to the physical settings

These were four problems related to the participants' speaking skills which were expressed in Figure 8. Unlike the two problems above, these difficulties seemed to have high rates in the states "Always", "Often" and "Sometimes". After analysis, it could be referred that "Intonation and Stress" was the one which students had to deal with more regularly. The statistic showed that 28 students voted for "Always" was also the highest rate compared to the same states of other difficulties. In addition, 55 responses in "Often" and 45 responses in "Sometimes" were the numbers that were rather high. The explanation for this was probably because they did not have enough presenting skills, then creating their fear of public speaking. The anxiety probably made the students not be able to handle their speed, they might speak too fast without remembering to pause or might speak too slow. Moreover, not everyone had enough confidence to address in front of many people. In addition, forgetting the stress in words or sentences was also a big concern, which could lead the audiences to feel bored and to lose concentration on the presentations. 




Figure 8. Problems related to participants' speaking skills

The next statistic about another problem was Figure 9, which indicated some problems related to participants' nonverbal communication. By and large, this chart could be compared with Figure 8 because the rates in "Always", "Often" and "Sometimes" were relatively the same. Look into the statistics, when compared to other difficulties, "Always" and "Often" states in "Eye contact" were the two which had the highest choice from students. The number of choices was 22 and 48 in turns. Although nonverbal communication was considered as one of the most important factors when giving presentations, many students still forgot to use it. The clarification for this was perhaps because of their anxiety when presenting. It means that they just focused only on presenting without remembering to maintain eye contact with their audiences.

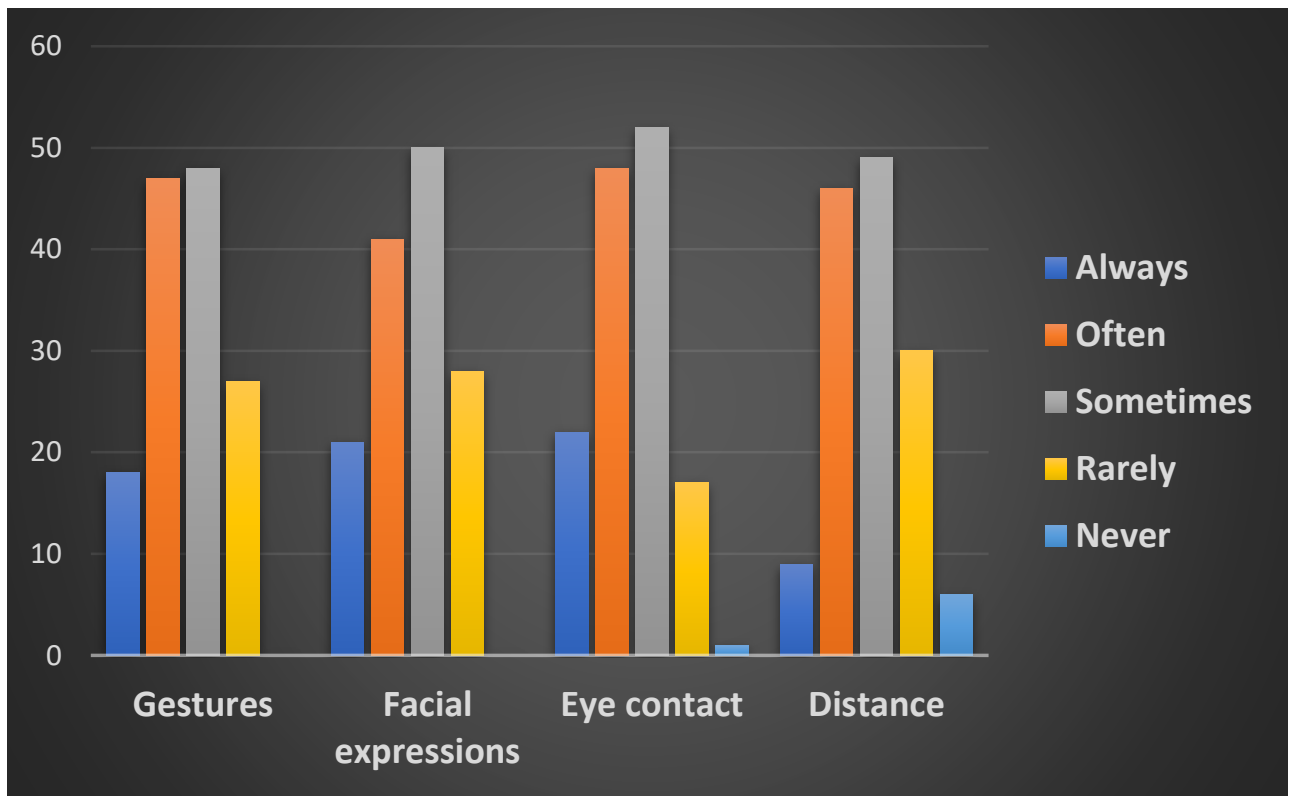

Figure 9. Problems related to the participants' nonverbal communication 
The last one was Figure 10, which displayed the four problems related to the audience. Generally speaking, this statistic was quite the same with the first two diagrams showing the high rates in "Often" and "Sometimes" states. Yet, there was a noticeable rate of "Lack of interaction". When compared to other difficulties, the statistic of "Often" was towered. The responses indicated that 61 students chose "Often" while others' statistics were just in a range from 20 people to 40 people. Due to an obvious fact that not all the topics were interesting. Combined with the lack of experience in giving a presentation; consequently, the audience would soon feel bored and lose concentration on the presentations.

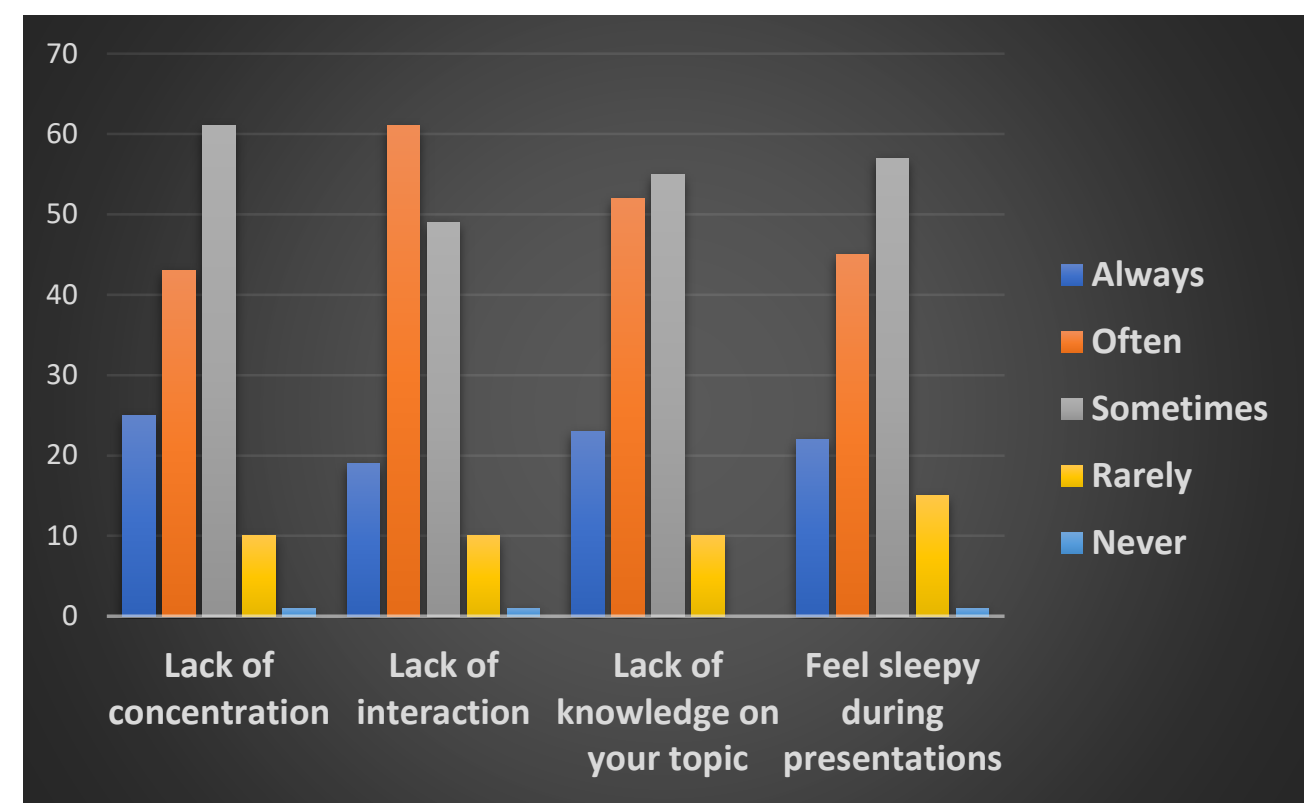

Figure 10. Problems related to the audiences

Last but not least, some suggested solutions for three stages Before-While-After presenting were described in Figure 11. For the first stage, the results demonstrated that "Select information and write down an outline carefully" was the most ideal solution which had the highest rate than others (75\%). Meanwhile, "Find out the interesting aspects of the topic you present" and "Practice many times with team-mates/ on your own" had nearly the same proportions (about 57\%) and they were about $18 \%$ lower than the highest one. In the next stage, three solutions had a slight difference in the number of votes. They are "Maintain contact with your audiences" (64.3\%), "Use your voice effectively" (45\%) and "Skip the contents you do not remember and continue presenting" (57.1\%). As shown in the charts, the last stage had a towering rate which is "Review feedbacks from the lecturers and other students" with $70.7 \%$. In short, these suggested solutions were just simply because each student would encounter different challenges, and they would also choose for their owns some suitable solutions. 

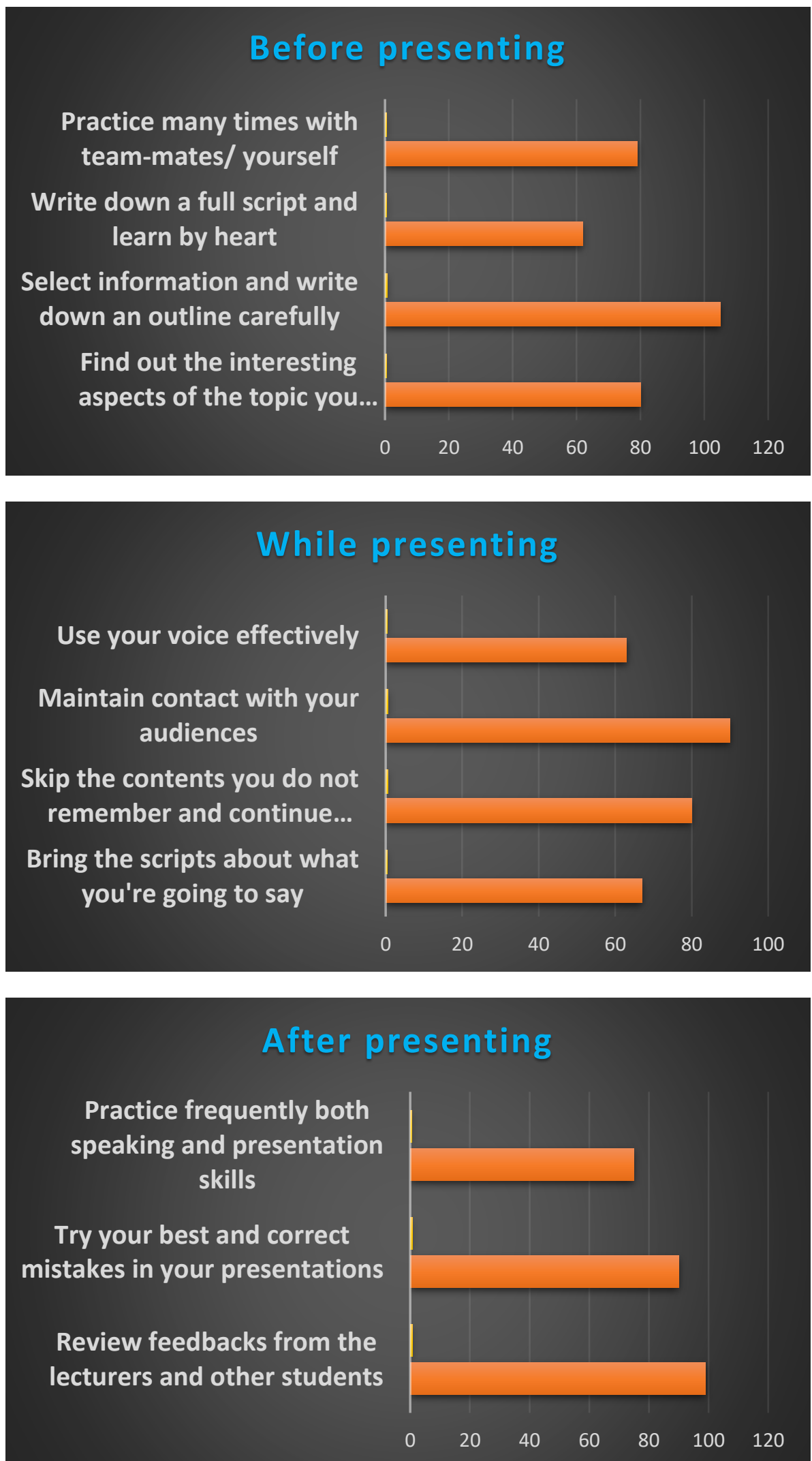

Figure 11. Some suggested solutions for three stages Before, While, and After presenting

This research was also similar to Otoshi and Heffernan's research (2008) which found similar outcomes compared to this one. In this study, the researchers suggested that teachers, before asking their students to deliver the presentations, should prepare them 
psychologically. The criteria of oral English presentations should be clarified. The main difficulties found in this research related to the difficulties under the first and third domains of the current research questionnaire. Similar problems found in this research such the presentations should be presented in a clear voice; the presentations should be done in an organized way, and so on. According to this research, the findings of this research were similar to the findings of the current one. The main challenges are found in terms of structures, objectives, clarity of voice, and audience interaction.

\section{Conclusions}

The aim of this research is to figure out the common difficulties which students often encounter when giving English presentations as well as different opinions between male and female students by conducting an online survey. However, the findings did not show major differences between the two groups. 140 students participating in the survey seem to have the same difficulties although $72.1 \%$ of participants thought that presenting in English is very important (Figure 4). One possible conclusion is that all of them faced problems in similar environments and the same frequencies.

The research' results were not completely perfect because the study was not only limited timewise but also restricted in terms of scales. As we knew, students from other courses also have had the same problems, it would be more valuable to carry on larger and diverse populations. It would also be interesting to observe students' improvements over several periods or to find out difficulties during the processes of preparing for the presentations instead of focusing only on the presenting stages.

The findings indicated that it does not matter if the students are male or female since all encounter the same issues when giving English presentations. The results also showed that the frequency of facing difficulties is often or sometimes (from Figure 6 to Figure 10). Additionally, our survey revealed that before presenting, students prefer to select information and write down an outline carefully; while presenting, they interact more with the audiences to avoid the silent atmosphere; and after completing the presentations, they tend to review feedback from the lecturers and other students (Figure 11).

The number of populations who face the above-mentioned difficulties could be more than this research scale, so it would be more fascinating to conduct experiments not only on students who are English majors but also on students who need to use English for their careers. Consequently, in the near future, a reinforcement of the effectiveness of the proposed solutions might also be necessary to help students gather further ways to improve their English presentation skills.

Likewise, more research should be encouraged to investigate in depth the challenges experienced by students at Ho Chi Minh City University of Food Industry in giving oral English presentations, as well as the social, linguistic, and psychological elements that influence presentation among students.

As a consequence, instructors should be able to assist their students in becoming better English presenters. The study results would contribute to this field by providing information and ideas on the oral English presentations which students utilize to deliver their academic tasks and be evaluated from the students' perspectives.

\section{Patents}

Funding: This research received no external funding 


\section{Appendix}

Survey Questionnaire for investigating difficulties in giving English presentations experienced by students at Ho Chi Minh City University of Food Industry

I. GENERAL INFORMATION

1. Full name:

2. Your gender:

a. Male

b. Female

c. Others

3. How long have you been studying English?

a. 5-10 years

b. 11-15 years

c. More than 15 years

d. -

4. How often do you take part in giving oral English presentations?

a. Every lesson

b. Once a week

c. Twice a week

d. -

5. Do you think that presentation skills are important for students?

a. Yes. They are very important.

b. No. They are only suitable for English Majors.

c. Neutral. It depends on what the major is.

d. -

6. How often have you had difficulties in giving English presentations?

a. Always

b. Often

c. Sometimes

d. Rarely 
e. Never

II. FREQUENCY OF RESPONDENTS ON PROBLEMS FACED IN ENGLISH PRESENTATIONS

Please put a mark on the box which is suitable for the level of the problems you have had. Each one refers to the following description.

- $\quad$ Always

- Often

- Sometimes

- Rarely

- Never

1. Problems related to the content of presentations

\begin{tabular}{|c|c|c|c|c|c|}
\hline & Always & Often & Sometimes & Rarely & Never \\
\hline $\begin{array}{c}\text { Unfamiliar } \\
\text { topics }\end{array}$ & & & & & \\
\hline $\begin{array}{c}\text { Disorganized } \\
\text { contents }\end{array}$ & & & & & \\
\hline $\begin{array}{c}\text { New gram- } \\
\text { mars and vo- } \\
\text { cabularies }\end{array}$ & & & & & \\
\hline
\end{tabular}

2. Problems related to physical settings

\begin{tabular}{|c|l|l|l|l|l|}
\hline & Always & Often & Sometimes & Rarely & Never \\
\hline Noise & & & & & \\
\hline $\begin{array}{c}\text { Poor quality } \\
\text { equipment } \\
\text { and facilities }\end{array}$ & & & & & \\
\hline $\begin{array}{c}\text { Limited } \\
\text { space }\end{array}$ & & & & & \\
\hline
\end{tabular}

3. Problems related to your Speaking skills

\begin{tabular}{|c|l|l|l|l|l|}
\hline & Always & Often & Sometimes & Rarely & Never \\
\hline $\begin{array}{c}\text { Speed of } \\
\text { speech }\end{array}$ & & & & & \\
\hline $\begin{array}{c}\text { Intonation } \\
\text { and Stress }\end{array}$ & & & & & \\
\hline
\end{tabular}




\begin{tabular}{|c|l|l|l|l|l|}
\hline $\begin{array}{c}\text { Pronuncia- } \\
\text { tion }\end{array}$ & & & & & \\
\hline Accent & & & & & \\
\hline
\end{tabular}

4. Problems related to your nonverbal communication

\begin{tabular}{|c|l|l|l|l|l|}
\hline & Always & Often & Sometimes & Rarely & Never \\
\hline Gestures & & & & & \\
\hline $\begin{array}{l}\text { Facial ex- } \\
\text { pressions }\end{array}$ & & & & & \\
\hline Eye contact & & & & & \\
\hline Distance & & & & & \\
\hline
\end{tabular}

5. Problems related to your audiences

\begin{tabular}{|c|l|l|l|l|l|}
\hline & Always & Often & Sometimes & Rarely & Never \\
\hline $\begin{array}{c}\text { Lack of con- } \\
\text { centration }\end{array}$ & & & & & \\
\hline $\begin{array}{c}\text { Lack of inter- } \\
\text { action }\end{array}$ & & & & & \\
\hline $\begin{array}{c}\text { Lack of } \\
\text { knowledge }\end{array}$ & & & & & \\
\hline $\begin{array}{c}\text { Feel sleepy } \\
\text { during } \\
\text { presentations }\end{array}$ & & & & & \\
\hline
\end{tabular}

\section{SOME SUGGESTED SOLUTIONS}

What would you do to overcome those difficulties in giving English presentations as well as improving your oral presenting skills?

You can choose more than one answer.

1. Before presenting

a. Find out the interesting aspects of the topic you present

b. Select information and write down an outline carefully

c. Practice many times with your teammates/ yourself 
d. Write down a full script and learn by heart

419

2. While presenting

a. Bring the script about what you are going to say

b. Skip the contents you cannot remember and continue presenting

c. Maintain eye contact with your audiences

d. Use your voice effectively

3. After presenting

a. Review feedback from the lecturers and other students

b. Try your best and correct mistakes in your presentations

c. Practice frequently both Speaking and Presentation skills 
13. Woodrow, L. (2006). Anxiety and speaking English as a second language. RELC Journal, 37(3), 308-328. doi:10.1177/0033688206071315 